\title{
Association of Highly Active Antiretroviral Treatment for HIV Disease and Metabolic Issues
}

\author{
Rajmonda Kolpepaj 1 \\ Enkelejda Shkurti² \\ Admir Nake ${ }^{3}$ \\ Arjan Harxhi ${ }^{4}$ \\ Emirvina Kolici ${ }^{5}$ \\ Keti Capi6 \\ 1,2,3,5Faculty of Technical Medical Sciences, University of Medicine, Tirana, Albania \\ "University Hospital Centre : "Mother Theresa", Tirana, Albania \\ ${ }^{6}$ Central Policlinic , Korca, Albania
}

\section{Doi:10.5901/ajis.2015.v4n1p153}

\section{Abstract}

Background: Highly active antiretroviral therapy (HAART) treatments, particularly those comprising protease inhibitors have been demonstrated to cause, in a majority of HIV-infected individuals, a metabolic syndrome (lipodystrophy/lipoatrophy, dyslipidemia, type 2 diabetes mellitus, insulin resistance) that may be correlated to with an augmented risk of cardiovascular disease. A cautious division in several groups of the cardiovascular risk of HIV infected people under HAART is required as said by the most current medical principles. Aim/methods: The aim of this review is to investigate the metabolic problems of treatments used to cure HIV infection. Results: They imply that HAART-linked lipodystrophy may be the outcome of adipocyte alteration engaging changeable mixtures of apoptosis, imperfect lipogenesis, and amplified metabolic action in diverse adipose body regions. In this survey, multivariate analysis made known that, between the inspected parameters, apo C-III was the single element powerfully connected with the incidence of lipodystrophy. Conclusion: Fat relocation may lead the progress of metabolic barriers in HIV-contaminated subjects getting HAART. The strictness of these metabolic deviations enhances with rising harshness of lipodystrophy, and they are related with an elevated threat of cardiovascular incidents: around 1.4 cardiac episodes per 1000 years of treatment regarding the Framingham result. Even if several surveys have revealed that the consume of glitazones for the cure of HIV-related lipodistrophy leads to an improvement in insulin resistance, contrasting results propose that additional labor is required.

Keywords: Human immunodeficiency virus, highly active antiretroviral therapy, nucleoside overturned transcriptase inhibitors, protease inhibitors, metabolic syndrome

\section{Introduction}

The foreword of highly active antiretroviral treatment (HAART) has considerably adjusted the itinerary of human immunodeficiency virus (HIV) syndrome, with extended survival and enhanced quality of life in HIV-infected patients.

Nevertheless, HAART treatments, principally those comprising protease inhibitors (PIs) have illustrated to cause in a greater part of HIV-infected subjects metabolic and physical alterations that in the common population are related to an amplified hazard of cardiovascular syndrome generating an interesting clinical outlook.

The foreword of highly active antiretroviral therapy (HAART), HIV- linked morbidity and mortality have turned down and continued existence and life worth have developed considerably in HIV-infected subjects with access to HAART (Lohse N et al 2007; Sterne JA, Hernan MA 2005)

HAART has altered a commonly lethal disease to a persistent, controllable communicable illness that entails enduring healing. Metabolic disease is an whole of central obesity and metabolic anomalies that presents an augmented threat of cardiovascular illness and type 2 diabetes (Tien PC et al 2007; NCEP 2002). Regarding preceding surveys, the occurrence of metabolic disease between HIV-infected subjects varies from $15.0 \%$ to 43.2\% (Jerico C 2005; Samaras K, 
Wand $\mathrm{H}$ 2007).

The dissimilarities in prevalence of metabolic disease amid the published surveys may be elucidated by the dissimilar survey populations and standards used and diverse inhabitants revised (Mondy K 2007; Sobieszczyk ME, Hoover DR 2008).

Whereas, the affiliation among metabolic disease and HAART is recognized, (Hoover DR 2008) the association amid every individual antiretroviral tool with metabolic disease is hard to describe since as a minimum two categories of antiretroviral instruments are concomitantly begun.

Nevertheless, it has been stated that the application of protease inhibitors (PIs) have to be correlated with metabolic syndrome (Samaras K 2007; Jacobson DL, Tang 2006). Of all nucleoside reverse transcriptase inhibitors (NRTIs), stavudine is the most commonly cited antiretroviral agent that is associated with metabolic syndrome (Jerico C 2005; Hansen BR, Petersen J 2009).

\section{Methodology}

The aim of this review is to investigate the metabolic problems of treatments used to cure HIV infection.

The progress of HAART-related metabolic disorder is multifaceted and a quantity of features are engaged, incorporating straight consequences of HAART on lipid metabolism, endothelial and adipocyte cell role, and mitochondria.

Pls target the catalytic region of HIV-1 protease. This region is homologous with regions of two human proteins that regulate lipid metabolism: cytoplasmic retinoic-acid binding protein-1 (CRABP-1) and low density lipoproteinreceptorrelated protein (LRP) ( Carr A et al 1998; Carr A, Samaras K, Chisholm DJ 1998).

It has been hypothesized, although without strong experimental support, that this homology may allow PIs to interfere with these proteins, which may be the cause of the metabolic and somatic alterations that develop in PIs-treated patients (Carr A et al 1998; Carr A, Samaras K, Chisholm DJ 1998).

The reticence enhances the speed of apoptosis of adipocytes and decreases the rate at which pre-adipocytes separate into adipocytes, with the ultimate outcome of diminishing triglyceride storage and augmenting lipid liberation. Pls-combination to LRP would harm hepatic chylomicron uptake and endothelial triglyceride clearance, generating hyperlipidemia and insulin resistance (Carr A et al 1998; Carr A, Samaras K, Chisholm DJ 1998).

Ultra structural investigation of adipocytes in PI- stimulated lipodystrophy exposes changes comprising distraction of cell membranes, divided cytoplasmic edges, irregular cell charts, and lastly fat droplets resting liberated in the connective tissue, with macrophages between them. Numerous adipocytes demonstrate variable division of fat globules with decline in cell dimensions and plentiful, mitochondria-affluent cytoplasm.

These results imply that HAART-linked lipodystrophy may be the outcome of adipocyte alteration engaging changeable mixtures of apoptosis, imperfect lipogenesis, and amplified metabolic action in diverse adipose body regions (Carr A, Samaras K, Chisholm DJ 1998).

Vernochet et al. appraised the consequence of six different PIs on the segregation of cells from three clone lines. It was investigated the ability of ritonavir to be found mutually into drug-susceptible and drug-resistant cultivated adipocytes (Vernochet $\mathrm{C}$ et al 2003).

The authors utilized a susceptible ELISA to establish intracellular concentration of ritonavir from 3T3- L1 and Ob1771 preadipocytes. Nelfinavir and lopinavir restrained adipocyte differentiation while amprenavir was useless. Indinavir, saquinavir and ritonavir restrained differentiation of 3T3-L1 and 3T3-F442A cells but did not modify differentiation of each Ob1771 or embryonic stem cells. The investigators illustrated that ritonavir gathered in preadipocytes and completely distinguished 3T3-L1 adipocytes as a role of its outside a cell concentration (Vernochet C et al 2003).

Regarding the outcomes of this experimental study PIs restrain adipocyte differentiation stipulating the cell pattern used. Ritonavir appears to build up into preadipocytes and adipocytes, implying a straight result on within cell targets.

Conversely, within cell gathering was obviously not adequate as Ob1771 cells were resistant to the delayed result of ritonavir (Vernochet C et al 2003).

Several records point out that Pls-related dyslipidemia may be partially the origin, either by PIs-interceded reservation of proteasome action and gathering of the dynamic section of sterol rigid element-requisite protein (SREBP)$1 \mathrm{c}$ in liver cells and adipocytes in HIV-infected subjects (Fauvel J\& Bonnet E 2001).

In this survey, multivariate analysis made known that, between the inspected parameters, apo C-III was the single element powerfully connected with the incidence of lipodystrophy (Bonnet E \& Ruidavets JB 2001). 
The progression homologies have been illustrated among HIV protease and human site-1 protease (S1P) that stimulates SREBP-1c and SREBP-2 trails.

This implies the presence of a genetic predisposition to hyperlipoproteinemia in PIs-treated patients (Caron $\mathrm{M}$ et al 2003). There is also evidence that PIs directly inhibit the uptake of glucose in insulin-sensitive tissues, such as fat and skeletal muscle, by selectively inhibiting the glucose transporter Glut4(Murata H \& Hruz PW 2000).

The correlation among the level of insulin resistance and ranks of solvable type-2-TNF-alpha receptor recommends that an inciting spur may contribute to the progress of HIV-allied lipodystrophy (Mynarcik DC 2000). TNF alpha stimulates 11-beta-hydroxysteroid dehydrogenase type-1 that transfers static cortisone to active cortisol. The movement of this enzyme is more elevated in visceral fat in contrast to subcutaneous fat. Visceral fat can generate cortisol that might proceed within adipocytes and raise lipid gathering (Gougeon ML \& Penicaud L 2004). There is data for nucleoside-stimulated mitochondrial failure in HIV-infected subjects cured with nucleoside holding HAART since lipodystrophy with tangential fat dissipating is linked with a regression in subcutaneous fat storing tissue mitochondrial DNA substance (Depairon M et al 2001). This result has been particularly explained with the application of stavudine and was connected with the duration of revelation to this medicine (Seminari E \& Tinelli C 2002).

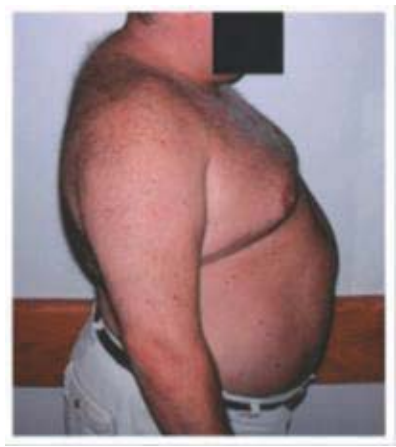

Fig 1. HAART-related fat relocation syndrome. Buffalo hump and raised abdominal girth. Courtesy of A. W. Karchmer, C. Mantzoros, and S. Tsiodras. Leow et al. • Clinical Review J Clin Endocrinol Metab, May 2003, 88(5):1961-1976

Adipocytes conceal a variety of adipocytokines which manage insulin sensitivity (Vigouroux C 2003). There are data that an adiponectin, a protein product of the apM1 gene, which is stated solely in adipocytes (Haque WA et al 2002), plays a role in development of HIV-linked lipodystrophy. Animal and cross-sectional surveys in humans have revealed that adiponectin is inversely compared with aspects of this metabolic syndrome as well as obesity, insulin resistance, type 2 diabetes, and coronary heart illness, as well as hereditary and acquired lipodystrophies in non-HIV contaminated subjects. This disorder has lately been associated to a quantitative locus on chromosome 3q27, the setting of the apM1 gene (Carr A, Samaras K; Burton S 1998).

Adiponectin was considerably connected with triglycerides, abdominal visceral fat, insulin resistance and high concentration lipoprotein (HDL) cholesterol stages by means of bivariate analysis.

In a study of 112 HIV-infected subjects getting HAART, (Carr A, Samaras K; Burton S 1998) the alliance of adiponectin with insulin resistance turned into non important after altering for NRTIs aplication, telling that alterations in adiponectin stages may lie beneath the deterioration result of NRTIs use on insulin resistance.

The insulin sensitivity was linked completely with adiponectin and unconstructively with leptin and interleukin- 6 (Vigouroux C 2003) in a assessment of 131 successive HIV-infected males under PIs-based HAART .

Parallel effects have been described moreover in a cross-sectional study by Kosmiski et al. (Kosmiski L, Kuritzkes D 2003) where adiponectin levels were notably and positively connected with insuline vulnerability after modification for fat gathering and adiponectin rank was an autonomous indicator of insuline sensitivity (Kosmiski L, Kuritzkes D 2003). 


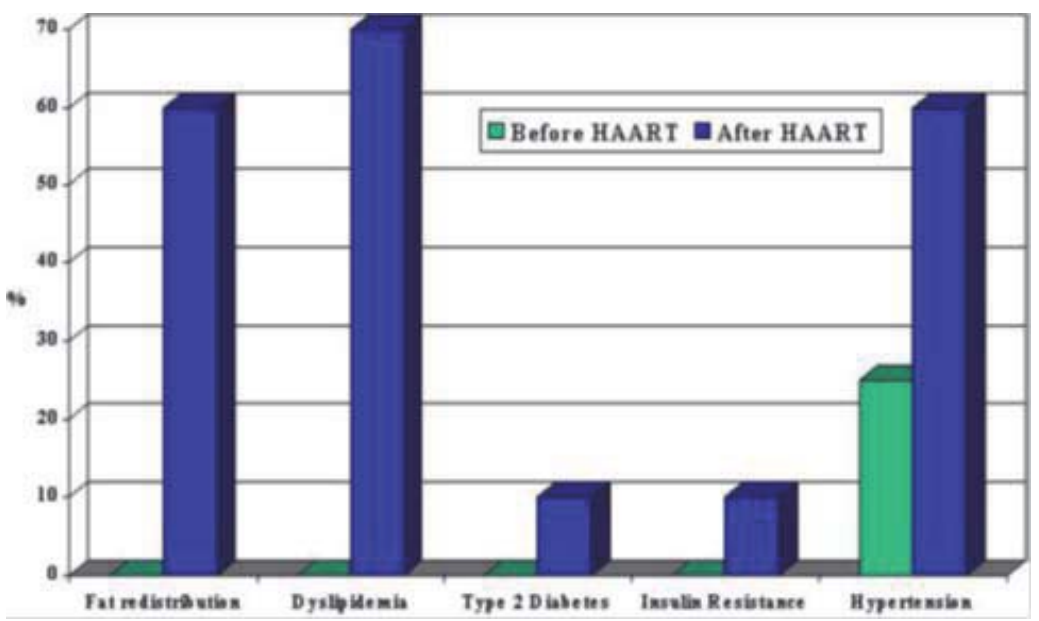

Fig. (2). Prevalence of the main medical and laboratory results inspected in HIV-infected subjects after the preface of HAART compare $d$ to the pre-HAART phase.

\section{Results}

The occurrence of the main clinical and laboratory conclusions noted in HIV-infected subjects later than the foreword of HAART contrasted to the pre-HAART stage is observed in Fig. 1.

Fat relocation. HIV-allied lipodystrophy undescribed prior to the preface of HAART, was first illustrated in 1998 (Carr $\mathrm{A}$ et al 1998). It is distinguished by the existence of a dorso-cervical fat filling enhanced abdominal restraint and breast dimension, lip atrophy of subcutaneous fat of the visage, buttocks and limbs, and distinction of veins on the extremities.

The usual occurrence of one corporeal deviation is thought to be about $47 \%$ in healthy HIV-infected subjects getting HAART, although reported rates vary since 16\% to 76\% [Grinspoon S\& Carr A 2005]. Changes in rates may be persuaded by age, gender, the sort and length of antiretroviral treatment, and the absence of a purpose and an authenticated case description (Grinspoon S\& Carr A 2005).

As in heritable lipodystrophy patterns (Garg A et al 2005), fat relocation may lead the progress of metabolic barriers in HIV-contaminated subjects getting HAART. The strictness of these metabolic deviations enhances with rising harshness of lipodystrophy, and they are related with an elevated threat of cardiovascular incidents: around 1.4 cardiac episodes per 1000 years of treatment regarding the Framingham result (Grinspoon S\& Carr A 2005). There is no scientifically verified remedy for any trait of lipodystrophy [ Carr A \& Samaras K 1998].

Amplified serum total and low density lipoprotein (LDL) cholesterol and triglyceride ranks have been detected in nearly $70 \%$ of HIV-contaminated subjects with lipodystrophy (Carr A \& Samaras K 1998).

Regarding lipodystrophy, an alternative in the handling of dyslipidemia in subjects getting PIs-counting HAART is to manage a mixture treatment without PIs [Carr A, Hudson J 2001; Clumeck N 2001]. Atazanavir, a novel azapeptide PI, appears not to be linked with important dyslipidaemia and insulin resistance as noticed with other PIs (Piliero PJ et al 2002). The outcomes of a stage 2 randomized test that evaluated lipid modifications after 32 weeks of treatment with atazanavir with those with nelfinavir (both in group with stavudine and lamivudine) demonstrated that ranks of total cholesterol and LDL cholesterol augmented extensively more between patients who applied nelfinavir $(+21 \%$ and +26 $\%$, correspondingly) than amid those who used atazanavir ( $+4 \%$ and $+1 \%$, respectively) (Grover SA \& Coupal L 2005).

Consistent with a recent study, lipid outline gets better by substituting PIs with efavirenz, nevirapine or abacavir with more distinct effects in non-lipodystrophic subjects. On the contrary, this approach does not look like to be valuable for repealing body fat deformities (Fisac C \& Fumero E 2005). In relation to another study the efavirenz-persuaded enhance in HDL-cholesterol is manipulated by the resistance gene 1 C3435T polymorphism (Alonso-Villaverde C 2005). 


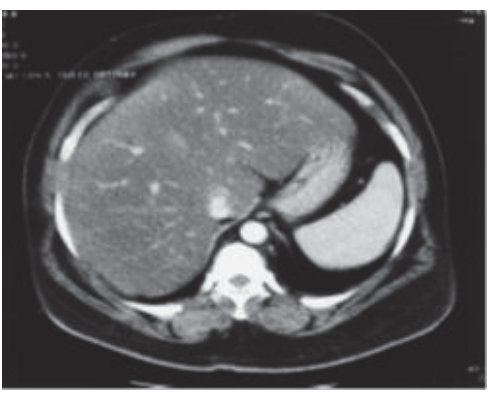

Fig 3. Abdominal CT scan illustrating hepatomegaly in a subject with HAART-linked lipodystrophy. Courtesy of Beth Israel Deaconess Medical Center (Boston, MA).

It has been noticed in $7 \%$ to $12 \%$ of the individuals with lipodystrophy the appearance of insulin resistance and type 2 diabetes mellitus (Carr A et al 2003). It is essential to memorize that various glitazones are by the CY3A4 trail, which could raise the danger of developing myositis and hepatitis if used concurrently with PIs.

The predominance of hypertension in HIV illness has been projected to be about $18-24 \%$ before the preface of HAART (Aoun S \& Ramos E. 2000). Hypertension is presently believed element of HAART-linked metabolic disorder [Gazzaruso C \& Bruno R 2003]. It seems to be connected to Pls-stimulated lipodystrophy and metabolic

syndrome with an occurrence of up to $68 \%$ in subjects with HAART-linked metabolic disorder (Gazzaruso C \& Bruno R 2003; Sattler FR 2001). When curing hypertension in HIV-infected patients with HAART-allied metabolic disorder, it should be distinguished that beta-blockers and diuretics might exacerbate the metabolic outlines of these subjects.

\section{Conclusions and Recommendations}

Principles for the administration of dyslipidemias in the universal population, like those of the National Cholesterol Education Plan also stand for the origin for therapeutic recommendations in HIV infected persons, as defined by the HIV Medicine Alliance of the Infectious Disease Society of US and by the Pavia Agreement Declaration (Volberding P et al 2003).

HAART treatment with didanosine plus stavudine appear to create a larger enhance in serum lactate and lipodystrophy than remedies derived from zidovudine plus lamivudine in the initial year of treatment (Depairon $\mathrm{M}$ \& Chessex S 2001). Replacement of stavudine with abacavir or zidovudine advances mitochondrial indices and fat apoptosis in the location of lipoatrophy [McComsey GA 2005]

Even if several surveys have revealed that the consume of glitazones for the cure of HIV-related lipodistrophy leads to an improvement in insulin resistance, contrasting results propose that additional labor is required (Carr A, Workman C \& Carey D 2004).

There are no communications among NRTIs and nucleotide reverse transcriptase inhibitors and anti-arrhythmics. Angiotensin-adapting enzyme inhibitors and angiotensin II-receptor blockers might be taken into account, but records from restricted clinical tests appraising these drugs in this division of patients are missing.

\section{References}

Lohse N, Hansen AB, Pedersen G et al (2007) Survival of persons with and without HIV infection in Denmark. Ann Intern Med; 146: 8795.

Sterne JA, Hernan MA, Ledergerber B et al (2005) Long-term effectiveness of potent antiretroviral therapy in preventing AIDS and death: a prospective cohort study. Lancet; 366 : 378-84.

Tien PC, Schneider MF, Cole SR et al (2007)Antiretroviral therapy exposure and incidence of diabetes mellitus in the Women's Interagency HIV Study. AIDS; 21: 1739-45.

Third Report of the National Cholesterol Education Program (NCEP) Expert Panel on Detection, Evaluation, and Treatment of High Blood Cholesterol in Adults (Adult Treatment Panel III) final report. Circulation (2002); 106: 3143-421.

Jerico C, Knobel H, Montero M et al.( 2005) Metabolic syndrome among HIV-infected patients: prevalence, characteristics, and related factors. Diabetes Care; 28: 132-7.

Samaras K, Wand H, Law M et al. (2007) Prevalence of metabolic syndrome in HIV-infected patients receiving highly active antiretroviral therapy using International Diabetes Foundation and Adult Treatment Panel III criteria: associations with insulin resistance, 
disturbed body fat compartmentalization, elevated C-reactive protein, and [corrected] hypoadiponectinemia. Diabetes Care; 30: $113-9$.

Mondy K, Overton ET, Grubb J et al. (2007) Metabolic syndrome in HIV-infected patients from an urban, midwestern US outpatient population. Clin Infect Dis; 44: 726-34.

Sobieszczyk ME, Hoover DR, Anastos K et al. (2008) Prevalence and predictors of metabolic syndrome among HIV-infected and HIVuninfected women in the Women's Interagency HIV Study. J Acquir Immune Defic Syndr; 48: 272-80.

Hansen BR, Petersen J, Haugaard SB et al. (2009) The prevalence of metabolic syndrome in Danish patients with HIV infection: the effect of antiretroviral therapy. HIV Med; 10: 378-87

Jacobson DL, Tang AM, Spiegelman D et al. (2006) Incidence of metabolic syndrome in a cohort of HIV-infected adults and prevalence relative to the US population (National Health and Nutrition Examination Survey). J Acquir Immune Defic Syndr; 43: 458-66.

Carr A, Samaras K, Burton S, Law M, Freund J, Chisholm DJ, Cooper DA. (1998). A syndrome of peripheral lipodystrophy, hyperlipidaemia and insulin resistance in patients receiving HIV protease inhibitors. AIDS 12: F51-F58.

Carr A, Samaras K, Chisholm DJ, Cooper DA. (1998). Pathogenesis of HIV-1-protease inhibitor-associated peripheral lipodystrophy, hyperlipidaemia, and insulin resistance. Lancet 351: 1881-1883.

Vernochet C, Azoulay S, Duval D, Guedj R, Ailhaud G, Dani C(2003). Differential effect of HIV protease inhibitors on adipogenesis: intracellular ritonavir is not sufficient to inhibit differentiation. AIDS 17: 2177-2180

Fauvel J, Bonnet E, Ruidavets JB, Ferrières J, Toffoletti A, Massip P, Chap H, Perret B. (2001). An interaction between apo C-III variants and protease inhibitors contributes to high tiglyceride/low HDL levels in treated HIV patients. AIDS 15: 2397-2406

Bonnet E, Ruidavets JB, Tuech J, Ferrieres J, Collet X, Fauvel J, Massip P, Perret B. (2001). Apoprotein C-III and E-containing lipoparticles are markedly increased in HIV-infected patients treated with protease inhibitors: association with the development of lipodystrophy. Journal of Clinical Endocrinology and Metabolism 86: 296-302

Caron M, Auclair M, Sterlingot H, Kornprobst M, Capeau J. (2003). Some HIV protease inhibitors alter lamin A/C maturation and stability, SREBP-1 nuclear localization and adipocyte differentiation. AIDS 17: 2437-2444.

Murata H, Hruz PW, Mueckler M. (2000). The mechanism of insulin resistance caused by HIV protease inhibitor therapy. Journal of Biological Chemistry 275: 20251-20254

Mynarcik DC, McNurlan MA, Steigbigel RT, Fuhrer J, Gelato MC. (2000). Association of severe insulin resistance with both loss of limb fat and elevated serum tumor necrosis factor receptor levels in HIV lipodystrophy. Journal of Acquired Immune Deficiency Syndromes 25: 312-321.

Gougeon ML, Penicaud L, Fromenty B, Leclercq P, Viard JP, Capeau J. (2004). Adipocytes targets and actors in the pathogenesis of HIV-associated lipodystrophy and metabolic alterations. Antiviral Therapy 9: 161-177.

Depairon M, Chessex S, Sudre P, Rodondi N, Doser N, Chave JP, Riesen W, Nicod P, Darioli R, Telenti A, Mooser VwtSHCS.(2001). Premature atherosclerosis in HIV-infected individuals: focus on protease inhibitor therapy. AIDS 15: 329-334.

Seminari E, Tinelli C, Minoli L, Sacchi P, Filice G, Zocchetti C,Meneghetti G, Bruno R, Maserati R. (2002). Evaluation of the riskfactors associated with lipodystriphy development in a cohort of HIV-positive patients. Antiviral Therapy 7: 175-180.

McComsey GA, Paulsen D, Lonergan JT, Hessenthaler SM, Hoppel CL, Williams VC, Fisher RL, Cherry CL, White-Owen C, Thompson KA, Ross ST, Hernandez JE, Ross LL. (2005). Improvements in lipoatrophy, mitochondrial DNA levels and fat apoptosis after replacing stavudine with abacavir or zidovudine. AIDS 19: 15-23.

Vigouroux C, Maachi M, Nguyen TH, Coussieu C, Gharakhanian S, Funahashi T, Matsuzawa Y, Shimomura I, Rozenbaum W, Capeau J, Bastard JP. (2003). Serum adipocytokines are related to lipodystrophy and metabolic disorders in HIV-infected men under antiretroviral therapy. AIDS 17: 1503-1511.

Haque WA, Shimomura I, Matsuzawa Y, Garg A. (2002). Serum adiponectin and leptin levels in patients with lipodystrophies. Journal of Clinical Endocrinology and Metabolism 87: 2395-2398.

Vigouroux C, Maachi M, Nguyen TH, Coussieu C, GharakhanianS, Funahashi T, Matsuzawa Y, Shimomura I, Rozenbaum W, Capeau J, Bastard JP. (2003). Serum adipocytokines are related to lipodystrophy and metabolic disorders in HIV-infected men under antiretroviral therapy. AIDS 17: 1503-1511.

Kosmiski L, Kuritzkes D, Lichtenstein K, Eckel R. (2003). Adipocyte-derived hormone levels in HIV lipodystrophy. Antiviral Therapy 8: 915.

Grinspoon S, Carr A. (2005). Cardiovascular risk and body-fat abnormalities in HIV-infected adults. New England Journal of Medicine 352: 48-62.

Garg A. (2005). Acquired and inherited lipodystrophies. New England Journal of Medicine 350: 1220-1234.

Volberding P, Murphy R, Barbaro G, Barbarini G, Bruno R, Cirelli A, Currie P, Di Lorenzo G, Fantoni M, Filice G, Galli M, Grisorio B, Moroni M, Recusani F, Sacchi P, Scevola D, Torre D, Vittecoq D. (2003). The Pavia Consensus Statement. AIDS 17 (S1): S170S179.

Carr A, Hudson J, Chuan J, Mallal S, Law M, Hoj J, Doong N, French M, Smith D, Cooper DA. (2001). HIV protease inhibitor substitution in patients with lipodystrophy: a randomized, controlled, open-label, multicentre study. AIDS 15: 1811-1822.

Clumeck N, Goebel F, Rozenbaum W, Gerstoft J, Staszewski S, Montaner J, Johnson M, Gazzard BG, Stone C, Athisegaran R, Moore S. (2001). Simplification with abacavir-based triple nucleoside therapy versus continued protease inhibitor-based highly active antiretroviral therapy in HIV-1-infected patients with undetectable plasma HIV-1 RNA. AIDS 15: 1517-1526

Ruiz L, Negredo E, Domingo P, Paredes R, Francia E, Balague M, Gel S, Bonjoch A, Fumaz CR, Johnston S, Romeu J, Lange J, Clotet B. (2001). Antiretroviral treatment simplification with nevirapine in protease inhibitor-experienced patients with hivassociated 
lipodystrophy: 1-year prospective follow-up of a multicenter, randomized, controlled study. Journal of Acquired Immune Deficiency Syndromes 27: 229-236.

Piliero PJ. (2002). Atazanavir: a novel HIV-protease inhibitor. Expert Opinion on Investigational Drugs 11: 1295-301.

Grover SA, Coupal L, Gilmore N, Mukherjee J. (2005). Impact of dyslipidemia associated with highly active antiretroviral therapy (HAART) on cardiovascular risk and life expectancy. American Journal of Cardiology 95: 586-591.

Fisac C, Fumero E, Crespo M, Roson B, Ferrer E, Virgili N, Ribera E, Gatell JM, Podzamczer D. (2005). Metabolic benefits 24 months after replacing a protease inhibitor with abacavir,efavirenz or nevirapine. AIDS 19: 917-925

Alonso-Villaverde C, Coll B, Gomez F, Parra S, Camps J, Joven J, Masana L. (2005). The efavirenz-induced increase in HDLcholesterol is influenced by the multidrug resistance gene 1 C3435T polymorpism. AIDS 19: 341-342.

Carr A. (2003). HIV lipodystrophy: risk factors, pathogenesis, diagnosis and management. AIDS 17 (S1): S141-S148.

Carr A, Workman C, Carey D, Rogers G, Martin A, Baker D, Wand H, Law M, Samaras K, Emery S, Cooper DA, Rosey investigators. (2004). No effect of rosiglitazone for treatment of HIV-1 lipoatrophy: randomised, double-blind, placebo-controlled trial. Lancet 363: 429-438.

Aoun S, Ramos E. (2000). Hypertension in the HIV-infected patient. Current Hypertension Reports 2: 478-481.

Gazzaruso C, Bruno R, Garzaniti A, Giordanetti S, Fratino P, Sacchi P, Filice G. (2003). Hypertension among HIV patients: prevalence and relationship to insulin resistance and metabolic syndrome. Journal of Hypertension 21: 1377-1382.

Sattler FR, Qian D, Louie S, Johnson D, Briggs W, DeQuattro V, Dube MP. (2001). Elevated blood pressure in subjects with lipodystrophy. AIDS 15. 
